Cadernos de

ESTUDOS LINGUÍSTICOS - (58.1), Campinas, pp. 45-62 - jan./abr. 2016

\title{
POLÊMICA DISCURSIVA NAS MANIFESTAÇÕES ANTI E PRÓ GOVERNO DILMA ROUSSEFF
}

\author{
EDVANIA GOMES DA SILVA* \\ ALESSANDRA SOUZA SILVA**
}

\begin{abstract}
RESUMO: Neste artigo, analisamosdiscursos materializados na mídia escrita acerca das manifestações anti e pró Governo Dilma Rousseff/PT/Lula, observando a existência de uma polêmica discursiva entre dois posicionamentos, ambos vinculados ao campo político. Trata-se, mais especificamente, de verificar o funcionamento das palavras impeachment e golpe, cujo efeito de sentido vai sendo construído de acordo com os lugares ideológicos de cada grupo. Na análise, recorremos aos pressupostos teóricos de Michel Pechêux, principalmente ao conceito de discurso,e à noção de polêmica discursiva, cunhada por Dominique Maingueneau, ambos autores vinculados à Escola Francesa de Análise de Discurso. Os resultados mostraramque a polêmica entre os anti e os pró Dilma/PT/Lula se fundamenta na forma como o campo político partidário se apropria de conceitos do campo filosófico, como o de bom senso, o de honestidade, e o de justiça.
\end{abstract}

Palavras-chave: discurso; política; polêmica discursiva.

ABSTRACT: In this article, we analyze speeches materialized in the print media about the manifestations anti and pro government Dilma Rousseff / PT / Lula, noting the existence of a discursive controversy between two positions, both linked to the political field. It is, more specifically, about verifying the operation of the words impeachment and coup, whose direction of effect is being constructed in accordance with the ideological places of each group. In the analysis, we used the theoretical assumptions of Pêcheux, especially the concept of speech, and the notion of discursive controversy coined by Dominique Maingueneau, both authors linked to the French School of Discourse Analysis. The results showed that the controversy between anti and pro Dilma / PT / Lula is based on how the partisan political field appropriates the concepts of philosophical field, such as common sense, honesty, and justice.

Keywords: speech; policy; discursive controversy.

\section{DISCURSO, INTERDISCURSO E POLÊMICA}

Neste artigo, analisamos discursos materializados na mídia acerca das manifestações anti e pró Governo Dilma Rousseff/PT/Lula, observando a

* Professora na Universidade Estadual do Sudoeste da Bahia (UESB), membro do Centro de Pesquisa FESTA - Fórmula e Estereótipos: teoria e análise e do GPADis - Grupo de Pesquisa em Análise de Discurso. e-mail: edvaniagsilva@gmail.com

** Mestre em Linguística pela Universidade Estadual do Sudoeste da Bahia, membro do GPADis - Grupo de Pesquisa em Análise do Discurso. e-mail: ale.souza01@hotmail.com 
existência de uma polêmica discursiva entre dois posicionamentos, ambos vinculados ao campo político. Para tanto, recorremos aos conceitos de discurso, interdiscurso e polêmica discursiva, todos desenvolvidos com base no quadro teórico-analítico da Escola Francesa de Análise de Discurso. A delimitação do objeto e a articulação das principais teses da referida disciplina foram elaboradas por Michel Pêcheux.

Para Pêcheux, o discurso deve ser compreendido, ao mesmo tempo, como uma estrutura, historicamente determinada, e também como um acontecimento. Trata-se, portanto, da relação entre uma atualidade e uma memória, pois, até mesmo uma estrutura linguística (palavra ou expressão) - aparentemente fechada sobre si mesma, com uma significação supostamente rígida, concreta e absoluta - pode mudar sua significação a depender do lugar/campo em que funciona, já que todo enunciado linguístico é, por isso mesmo, uma estrutura, mas é também histórico e, portanto, um acontecimento (PÊCHEUX, 2008). Dessa forma, discurso é definido como efeito de sentido que se materializa na língua.Trata-se, mais especificamente, de analisar a língua produzindo sentidos, sendo afetada pelo simbólico, pelo histórico e pelo social.

$\mathrm{Na}$ AD, busca-se, portanto, compreender o discurso a partir da relação entre língua, história e sociedade, considerando os movimentos que os sentidos percorrem e o interdiscurso que os sustenta, uma vez quetodo dizer se apoia sempre em outros dizeres, retoma sempre outras vozes.

Maingueneau (2005) propõe que o interdiscurso está inserido em uma perspectiva teórica na qual há uma precedência do Outro sobre o Mesmo. De acordo com o referido autor, a hipótese do primado do interdiscurso inscrevese na perspectiva de uma heterogeneidade constitutiva, que "amarra, em uma relação inextricável, o Mesmo do discurso e seu Outro" (MAINGUENEAU, 2005, p 33). Ainda segundo Maingueneau, a questão do interdiscurso está presente, sob diferentes perspectivas, na psicanálise, nas teorias da enunciação, da ideologia e do discurso; e o que torna formulações de diferentes campos aparentemente vizinhas é o fato de todas elas remeterem, de certa forma, aos trabalhos de Bakhtin, "sobretudo os trabalhos sobre Dostoievsky e Rabelais" (MAINGUENEAU, 2005, p. 34). Contudo, apesar de reconhecer que sua hipótese do primado do interdiscurso também se inscreve, em alguma medida, na perspectiva bakhtiniana de uma "heterogeneidade constitutiva", Maingueneau (2005) afirma operar em um quadro mais restrito, pois atribui "a essa orientação geral um quadro metodológico e um domínio de validade muito mais precisos" (MAINGUENEAU, 2005, p. 35).

Nesse sentido, a partir da noção mais geral de interdiscurso, Maingueneau delimita a existência da tríade: universo, campo e espaço discursivos. O universo discursivo é o termo mais amplo e corresponde ao conjunto de discursos que interagem em uma conjuntura dada, sendo, portanto, inacessível ao analista. O campo discursivo, ainda segundo Maingueneau, corresponde ao conjunto de discursos "que se encontram em concorrência, delimitando-se reciprocamente em uma região determinada do universo discursivo" (MAINGUENEAU, 2005, p. 35). Diz respeito, portanto, a diferentes "recortes", os quais "delimitam 46 
Cadernos de ESTUDOS LINGUÍSTICOS (58.1) - jan./abr. 2016

discursos que possuem a mesma função social, mas divergem sobre o modo pelo qual ela deve ser preenchida" (Idem, p. 36). Podemos falar, assim, do campo político, filosófico, religioso, etc. Contudo, ainda segundo Maingueneau, não é possível determinar, no campo, todas as modalidades (ou formas) de relação que se dão entre os diferentes discursos. É por isso que surge a necessidade de delimitarmos os espaços discursivos, pois, nesses espaços, que são construídos pelos analistas com base em certos critérios, é possível determinar o tipo de relação que se dá entre diferentes posicionamentos de um mesmo campo. É com base no estudo de dois posicionamentos que partilham de um mesmo espaço discursivo, o jansenismo e o humanismo devoto, que Maingueneau mostra o funcionamento da polêmica discursiva. A polêmica é, portanto, uma das formas de relação que pode se estabelecer entre dois discursos que partilham de um mesmo espaço.

Em um texto de 2010, Maingueneau volta a tratar do polêmico, caracterizando-o, agora, como um registro, que tem três dimensões. De acordo com o referido autor:

\footnotetext{
A inclusão do polêmico na lista dos registros (ao lado do trágico, do épico, do epidítico, do satírico, do fantástico etc.) não tem nada de surpreendente, dado que o termo "registro" pode a priore designar qualquer conjunto de traços linguísticos regularmente associados em um discurso, mas que não se caracterizam por ocorrerem em um único gênero (MAINGUENEAU, 2010, p. 187).
}

Maingueneau, afirma ainda que o polêmico tem a ver claramente com um registro de tipo comunicacional (assim como ocorre com o "discurso didático", o "discurso de divulgação" e o "discurso cômico") e está associado a um "repertório de traços linguísticos considerados característicos de certa 'violência' verbal" (MAINGUENEAU, 2010, p. 189). O autor salienta que o polêmico pertence aos "gêneros instituídos" e não à conversação. Desse ponto de vista, polêmica é um termo que deve ser usado em relação à "conflitos nos quais as questões estão situadas além dos indivíduos que interagem" (MAINGUENEAU, 2010, p. 190). Portanto, no caso do corpus aqui analisado, se ele de fato diz respeito a uma polêmica, trata-se de uma polêmica que ocorre em relação a dois posicionamentos que fazem parte do campo político e que podem ser analisados, com base na nossa percepção de analistas, dentro de um mesmo espaço discursivo, o qual constituímos a partir da constatação de que existe uma polarização na atual política-partidária brasileira. Essa polarização não é suficientemente marcada por uma oposição entre esquerda e direita, mas, talvez, uma das formas de mostrá-la seja definir uma oposição entre um posicionamento pró-Dilma/PT/Lula e um outro posicionamento anti-Dilma/PT/Lula.

Nesse sentido, a partir do conceito de discurso, conforme proposto por Pêcheux (1983), bem como da noção deinterdiscurso e de sua relação com o registro polêmico, conforme definido por Maingueneau $(2005,2010)$, mostramos como se estabelece a polêmica entre os posicionamentos pró e antiDilma/Lula/PT, em circulação em diferentes manifestações ocorridas no país ao 
longo de 2015. Para tanto, analisamos fotografias ${ }^{1}$ das referidas manifestações, disponíveis na internet, e textos escritos, também acerca dessas manifestações, os quais foram publicados na versão brasileira do jornal El País ${ }^{2}$ (online). Por fim, mostramos a forma como esses dois posicionamentos abordaram, por meio de dois veículos de comunicação, as revistas Veja ${ }^{3}$ online e Carta Maior ${ }^{4}$, a condução coercitiva do presidente Lula, realizada pela Polícia Federal, no dia 4 de março de 2016.

\section{A POLÊMICA EM TORNO DE UM "PAÍS DIVIDIDO"}

"O país está divido". Esta afirmação está em circulação em diferentes enunciados, fazendo referência à série de manifestações (nas ruas, nas redes sociais, nos espaços públicos ou privados) acerca dos rumos do governo brasileiro. A expectativa positiva, que permeou o início do primeiro mandato do Governo Dilma ${ }^{5}$, deu lugar a uma onda de críticas ao referido governo, as quais começaram a ganhar força a partir das manifestações de junho de 2013, protagonizadas por brasileiros que moram tanto no país quanto no exterior.Essas manifestações,inicialmente, surgiram para contestar os aumentos nas tarifas de transporte público em diversas cidades brasileiras mas, posteriormente, passaram a reivindicar outras demandas, como, por exemplo, o fim da violência policial, a melhoria na qualidade dos serviços públicos, e o fim da corrupção nos governos.

Ao final do ano de 2014, após o resultado acirrado da disputa eleitoral, as críticas ao governo Dilma foram intensificadas. Embora reeleita para o segundo mandato de seu governo (e quarto do governo do PT), Dilma Rousseff se deparou com uma situação bem diferente de 2010, pois, desde o início do mandato, a rejeição da população ao governo foi uma constante. Iniciou-se, assim, um ciclo de manifestações com um tom até então desconhecido pela presidente: os discursos já

\footnotetext{
${ }^{1} \mathrm{Na}$ análise das fotografias, consideramos um outro conceito de Maingueneau (2005): o de prática intersemiótica. Segundo o referido autor, a existência de uma prática intersemiótica é uma hipótese que se baseia na noção de prática disursiva. A prática discursiva mostra que o discurso não se constitui apenas por meio de um conjunto de textos, mas deve ser pensado como uma prática, a qual torna os textos 'comensuráveis com a 'rede institucional' de um 'grupo', aquele que a enunciação discursiva ao mesmo tempo supõe e torna possível” (MAINGUENEAU, 2005, p. 23). Nessa perspectiva, a prática intersemiótica "integra produções que pertencem a outros domínios semióticos (pictórico, musical, etc...). Tal extensão torna-se necessária pelo fato de que o sistema de restrições que funda a existência do discurso pode ser igualmente pertinente para esses outros domínios" (MAINGUENEAU, 2005, p. 23).

${ }^{2}$ Www.brasil.elpais.com

${ }^{3}$ www.veja.abril.com.br

${ }^{4}$ www.cartamaior.com.br

${ }^{5}$ Em 2011, iniciou-se o terceiro mandato do Governo do PT, com a presidente Dilma Rousseff eleita com pouco mais de $56 \%$ dos votos válidos. A expectativa para seu primeiro governo, de acordo com Barbosa (2014), era otimista. Havia uma relação de identificação dos brasileiros com a imagem da presidente, cuja relação com o Partido dos Trabalhadores era silenciada, e seu governo, embora mantendo relações com o ex-presidente Lula, era marcado discursivamente por uma série de práticas que o distinguiam de seu antecessor e o distanciavam dos casos de corrupção.
} 
Cadernos de ESTUDOS LINGUÍSTICOS (58.1) - jan./abr. 2016

não eram mais por uma mudança na forma de governar, mas por uma mudança de governo, pedindo a saída da presidente eleita. Até o momento de conclusão deste artigo, foram quatro grandes manifestações contra o governo Dilma Rousseff (em 15 de março, 12 de abril, 16 de agosto e 13 de dezembro de 2015 ), as quais levaram milhares de pessoas às ruas de todo o Brasil. Os temas principais dessas manifestações foram o pedido de impeachment da presidente Dilma, bem como sua culpabilização, em conjunto com o PT e o ex-presidente Lula $^{7}$, pela situação de crise econômica que o país estaria enfrentando e pelo esquema de corrupção na Petrobrás. A esse respeito, vejamos as seguintes imagens:

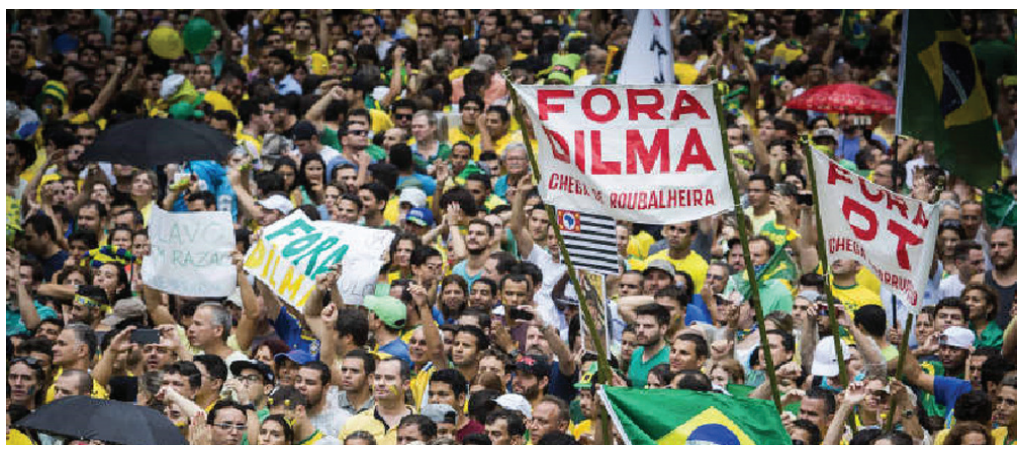

Figura 1: Protesto contra o governo Dilma, na Avenida Paulista,

São Paulo, em 15 /03/2015 (Foto: Bruno Santos/Veja.com)

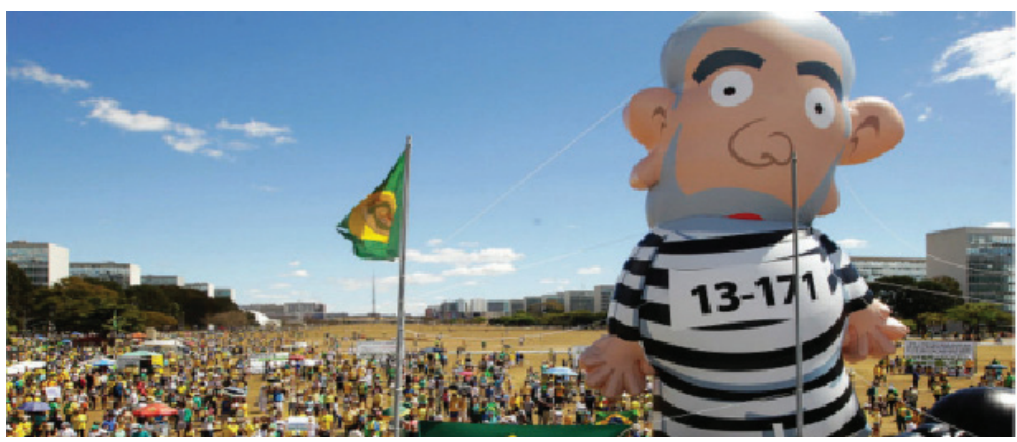

Figura 2: Lula vestido como presidiário em manifestação no Distrito Federal em 16/08/2015 (Foto: Cristiano Mariz/Veja.com)

Na figura 1, vemos um grupo de pessoas vestido, em sua maioria, de verde e amarelo, segurando algumas bandeiras do Brasil, o que cria um efeito de sentido de patriotismo, e algumas bandeiras e cartazes com os enunciados "Fora Dilma, chega de roubalheira" e "Fora PT, chega de roubalheira". Tais enunciados fazem

${ }^{6}$ Uma nova manifestação já está prevista para o dia 13 de março de 2016.

${ }^{7} \mathrm{O}$ ex-presidente Luís Inácio Lulas da Silva, do Partido dos Trabalhadoresfoi presidente do Brasil por dois mandatos consecutivos, no período de 2002 a 2010. Durante os seus dois mandatos, o governo Lula viu-se envolvido em diversas denúncias de corrupção, as quais não impediram, no entanto, que Lula terminasse seu segundo mandado com $80 \%$ de aprovação, de acordo com pesquisa Ibope encomendada pela CNI (Confederação Nacional da Indústria), divulgada no dia 16 de dezembro de 2010. 
funcionar uma memória discursiva segundo a qual existe uma "roubalheira" no Brasil, cujos agentes são a presidente Dilma Rousseffe o Partido dos Trabalhadores, uma vez que, para que a "roubalheira" acabe, é necessário que a presidente Dilma e o PT saiam do governo. Na figura 2, assim como na 1, há uma multidão vestida de verde e amarelo, carregando bandeiras do Brasil. Todavia, essa imagem traz um elemento novo: um "boneco" gigante simbolizando o ex-presidente Luís Inácio Lula da Silva. O boneco está vestido com um uniforme que, por um efeito da memória discursiva que circula na sociedade, remete à imagem de um presidiário. Esse uniforme traz como número de identificação do "detento" o 13-171; o número 13 é o número da legenda do PT, enquanto o número 171 faz alusão, também por um efeito da memória discursiva, ao artigo 171 do código penal brasileiro, que se refere ao ato de estelionato, ou seja, ao ato de enganar alguém para conseguir algo em benefício próprio. Dessa forma, o enunciado materializa o efeito de sentido segundo o qual o ex-presidente Lula é um criminoso, uma vez que se apresenta como um presidiário; e que, tanto ele quanto o PT (simbolizado pelo número 13), são mentirosos, aproveitadores, indignos de confiança, pois enganaram aqueles que confiaram neles a fim de se beneficiarem.

Verificamos esses mesmos discursos em reportagens de alguns jornais que tratam das manifestações anti-governo, como mostra o excerto 1:

1. Entre gritos de "fora PT" e "Viva a PM", uma multidão marcha para contestar o resultado da eleição. O objetivo: promover um movimento que consiga o impeachment de Dilma. [...]. O escândalo na petroleira estatal, após se desvelar um suposto esquema de desvio de dinheiro para políticos, é o principal palanque dos manifestantes (El País, seção Brasil, 01/11/2014, grifos nossos).

Nesse excerto, destacamos, primeiramente, o enunciado "uma multidão marcha para contestar o resultado da eleição". Aqui, a expressão "uma multidão", em vez de "um grande número de pessoas" ou de "muita gente", por exemplo, indica uma direção argumentativa. Afinal, nenhum desses termos mostra de forma precisa quantas pessoas estavam na rua, eles apenas permitem ao enunciador assumir certa direção $\operatorname{argumentativa}{ }^{8}$. Nesse caso, a expressão "uma multidão",

\footnotetext{
${ }^{8}$ No texto "Pouco" e "um pouco", Ducrot (1977) mostra que algumas expressões, como é o caso de "pouco" e de "um pouco" não apresentam uma distinção de grau, mas situam-se em eixos semânticos distintos, por permitirem relações argumentativas diversas. Nesse sentido, Ducrot (1977) propõe "uma descrição radicalmente diferente [daquela que se fundamenta na distinção de grau], fundada num conceito semântico de uma espécie totalmente diversa (DUCROT, 1977, p. 204). Em um texto mais recente, Ducrot (2009) defende, com base na Teoria dos Blocos Semânticos (TBS), desenvolvida por ele e por Marion Carel, que numa frase, como "Pedro trabalhou pouco, ele vai, portanto, reprovar" ou "Pedro trabalhou um pouco, ele vai, portanto, conseguir", "ninguém jamais encontrou diferença factual, quantitativa, entre pouco e um pouco. A única diferença entre essas duas expressões reside nos tipos de encadeamentos possíveis a partir delas mesmas. /.../, o argumento A já anuncia a conclusão no sentido de que a própria significação de pouco ou um pouco comporta a indicação do que é possível encadear às proposições que contêm tais palavras. Desse modo, não há raciocínio, progresso cognitivo, transmissão de verdade, já que o portanto C já faz parte do sentido de A (DUCROT, 2009, p. 22-23). Esses dois textos mostram que expressões, como "pouco" e "um pouco", ou, no caso da análise do excerto 33, "uma multidão", que parecem, em princípio, indicar quantidades, indicam, na verdade, a direção argumentativa assumida pelo enunciador.
} 
Cadernos de ESTUDOS LINGUÍSTICOS (58.1) - jan./abr. 2016

além de conferir legitimidade ao suposto pleito pelo "impeachment de Dilma", pois mostra que esse é o desejo de "uma multidão", produz um efeito da memória sobre a atualidade, pois "multidão" remete a outros acontecimentos históricos em que um grande número de pessoas se reuniu em prol de um objetivo comum. Esse efeito de memória é reforçado pelo verbo "marcha", que, ao determinar a ação de "multidão", reforça a memória de luta popular por um objetivo em comum, que, nesse caso, é definido, primeiro como "contestar o resultado da eleição", e depois como "promover um movimento que consiga o impeachment de Dilma". Assim, essas duas predicações são apresentadas numa relação de paráfrase, sendo ambas apontadas como o "objetivo da multidão". Ainda em relação ao excerto 1 , destacamos o enunciado "O escândalo na petroleira estatal é o principal palanque dos manifestantes". Nesse caso, o nome palanque, muito comum nos espaços de disputa política, indica o palco, o lugar de visibilidade onde os sujeitos envolvidos em uma disputa eleitoral, por exemplo, se apresentam, se mostram. Nesse sentido, ao relacionar a expressão referencial "O escândalo na petroleira estatal" com o predicativo "principal palanque dos manifestantes", o enunciador El Paiscria o efeito de sentido de que esse fato tem grande importância e visibilidade, sendo apresentado como um motivo suficientemente forte para se constituir como palanque dos manifestantes, que não apenas discordam do resultado das eleições, como pedem a saída do PT do governo e, consequentemente, da Presidente Dilma Rousseff.

Todavia, esse discurso que aponta o PT, Lula e Dilma como culpados pela situação do país, relacionada à economia e à corrupção, e pede a saída da presidente, não está sozinho nesse espaço discursivo. E, conforme defende Maingueneau (2005), quando dois discursos partilham de um mesmo espaço discursivo, eles estabelecem entre si uma relação de polêmica. Enquanto uma parcela da sociedade vai para as ruas defender as bandeiras supracitadas, outra parcela também vai às ruas, mas contrariamente aos que pedem o impedimento da presidente, essa outra parcela da sociedade opõe-se veementemente ao impeachment de Dilma, realizando manifestações, cujo tema central foi "a defesa da democracia", em 13 de março, 20 de agosto e 16 de dezembro de 2015, como podemos observar nas fotografias, a seguir:

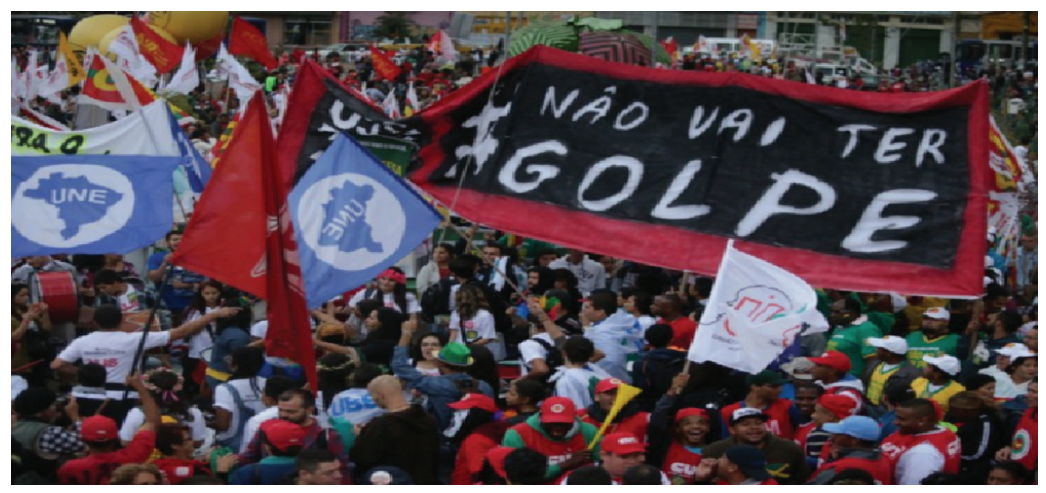

Figura 3: Manifestação contra o impeachment de Dilma, no Largo da Batata, 
em São Paulo, em 20/08/2015 (Fotos: Roberto Parizotti/Cut)

Em ambas as fotos, é possível verificar uma multidão vestida de vermelho, cor que simboliza o PT. Na foto da esquerda, vemos vários manifestantessegurando bandeiras de movimentos sociais e estudantis (União Nacional de Estudantes - UNE, Central dos Trabalhadores e Trabalhadora do Brasil -CTB, União da Juventude Socialista - UJS, etc.), o que produz o efeito de sentido de que tais movimentos sociais apoiam o governo; os manifestantes também seguram uma faixa com o enunciado "Não vai ter golpe", em alusão direta aos movimentos que pedem a saída da presidente Dilma, caracterizando esses movimentos como fruto de uma ação ilegal e ilegítima, um golpe. Na foto da direita, além da bandeira do Brasil e das faixas (na qual não foi possível identificarmos o que está escrito) os manifestantes portam um grande cartaz com o enunciado "Em defesa da Democracia! Dilma Fica!", em letras amarelas sob um fundo preto. Nesse enunciado, tem-se o pré-construído ${ }^{9}$ de que a democracia está em risco, já que é preciso defendê-la; além disso, a expressão "Dilma Fica" só pode existir, porque já existe um outro discurso em circulação, ao qual ele se opõe, que diz: "Dilma deve sair". Em continuidade às análises do cartaz, há, logo abaixo dos enunciados, uma faixa verde e amarela, que atualiza uma memória de patriotismo e se relaciona com o a expressão "democracia" e, logo abaixo desta, uma imagem de Dilma Rousseff ainda jovem (veiculada no período da eleição presidencial, acompanhadado slogan "Dilma, Coração valente") dentro do contorno do mapa do Brasil, desenhado com as cores da bandeira, sob um fundo vermelho. A cor vermelha, como dissemos anteriormente, faz alusão ao PT, partido da presidente. A utilização dessa foto de Dilma ainda jovem, e não deuma foto atual, retoma discursos acerca da coragem e da garra da presidente durante, sobretudo, o período da Ditadura Militar de 1964, amplamente veiculados durante a última campanha eleitoral. A foto de Dilma dentro do mapa do Brasil cria o efeito de sentido de que a atual presidente é a legítima representante do país. Por fim, ao lado da foto de Dilma, há uma pomba branca carregando no bico um ramo de oliveira, imagem que simboliza, entre os cristãos, o Espírito Santo, a paz e a esperança; a pomba voa em direção à imagem de Dilma e ao mapa do Brasil, criando o efeito de sentido de que o Espírito Santo está indo ao encontro de Dilma e do Brasil, levando para ambos, paz e esperança.

No entanto, embora essas manifestações sejam em defesa da permanência do governo Dilma, elas não apontam para uma satisfação completa com o mesmo, ao contrário, as manifestações pró-governo também tecem críticas a ele, cobrando, entre outras coisas, a manutenção de direitos trabalhistas, conforme verificamos nas imagens abaixo:

\footnotetext{
${ }^{9}$ O conceito de "pré-construído", cunhado por Pêcheux (1975), diz respeito a uma marca em um enunciado de um discurso anterior a ele, em outras palavras, é um já-dito que sustenta cada palavra e/ou enunciado, permitindo que seja realizada a remissão de um dizer a toda uma filiação de outros dizeres. Corresponde, assim “ao 'sempre-já-aí' da interpelação ideológica que fornece-impõe a 'realidade' e seu 'sentido' sob a forma da universalidade” (PÊCHEUX, 1975, p. 164).
} 


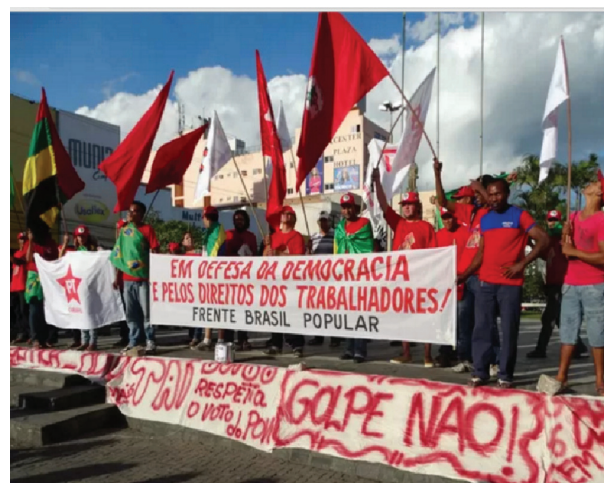

Figura 4: Manifestação em defesa do governo Dilma, em Caruaru em 20/08/15

(Foto: Joalline Nascimento/ G1)

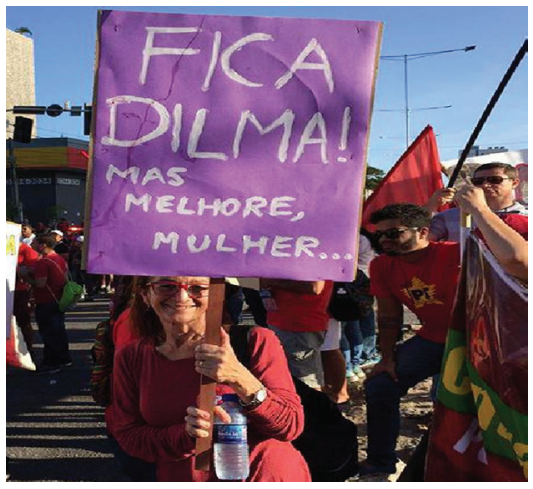

Figura 5: Manifestação em Natal, em 20/08/15

(Foto: MárlioForte/watterbatista.com)

As figuras 4 e 5,assim como as anteriores, apresentam manifestantes vestidos de vermelho e segurando bandeiras de movimentos sociais. No entanto, trazem mais alguns elementos: na figura 4, lemos, na parte inferior da faixa, as inscrições "Respeita o voto do povo" e "Golpe Não"; e na faixa que está no centro da imagem, vemos as inscrições "Em defesa da Democracia e pelos Direitos dos Trabalhadores! Frente Brasil Popular". O enunciado "Respeita o voto do povo" traz um préconstruído segundo o qual existe uma tentativa ou uma intenção de desrespeitar o voto do povo. Além disso, o enunciado "Golpe Não", que está na mesma faixa, cria o efeito de sentido de que esse desrespeito ao voto do povo está relacionado a uma tentativa de golpe que ainda não se efetivou, uma vez que o enunciado "Golpe Não" pode ser parafraseado como "não aceitarei o golpe". A outra faixa, embora também mostre-se contrária a um suposto golpe, uma vez que aponta para a necessidade de defesa da democracia, indica também a necessidade de defesa dos direitos dos trabalhadores, pois, de acordo com o discurso materializado na referida faixa, esses direitos, assim como a democracia, estão ameaçados. Por um efeito da memória sobre o acontecimento, temos, ao menos, duas interpretações possíveis para esse enunciado. Uma é a de que o próprio governo está, devido a sua forma de governar, ameaçando os direitos trabalhistas; a outra aponta para um desrespeito que estaria ligado aos supostos "golpistas", ou seja, aqueles que defendem o impeachmentda presidente Dilma Rousseff. Nesse caso, "direito dos trabalhadores"corresponde ao direito de manter no poder quem eles escolheram para estar lá. O interessante, nesse caso, é que fatores extratextuais, como o fato de o cartaz ter sido veiculado em uma manifestação pró-governo Dilma, indicam que o efeito de sentido que está em funcionamento é o segundo, entretanto, justamente porque o discurso não pode ser pensado como um bloco fechado, mas sempre na relação com o interdiscurso, é que, independentemente, da intenção de quem faz a faixa, o primeiro efeito de sentido, isto é, o de que o próprio governo Dilma está, em alguma medida, "ferindo" o direito dos trabalhadores, também faz parte da interpretação do referido enunciado. Ainda segundo essapossibilidade 
de interpretação, a manifestação materializada na/pela fotografia defende a permanência do governo, como um ato democrático, mas também faz críticas a ele; o que é corroborado na imagem seguinte, em que uma mulher vestida de vermelho carrega um cartaz com o seguinte enunciado: "Fica Dilma! Mas melhore, mulher...". Nesse caso,embora haja a afirmação de que Dilma deve continuar no governo, o operador argumentativo "mas" introduz uma condição para que ela fique: ela precisa "melhorar", o que remete a uma memória segundo a qual o governo Dilma Rousseff não está correspondendo às expectativas de seus próprios partidários, ou, pelo menos, de alguns deles.

Esse discurso de que o governo Dilma precisa "melhorar", também está materializado em outros textos que circulam na mídia acerca das manifestações:

\begin{abstract}
Sindicatos e movimentos sociais promovem ato pró-democracia
Confederações de trabalhadores, semteto e semterra promovem manifestação dois dias antes de um ato que pede o impeachment da presidenta.

Dois dias antes do ato que pedirá o impeachment da presidenta Dilma Rousseff, lideranças sindicais promovem protestos nesta sextafeira nas 27 capitais do país em apoio à Petrobras, a favor da democracia, e contra o chamado golpismo. Apesar de refutar a pauta dos protestos de domingo, que visam pedir o impeachment de Dilma, as centrais vão cobrar a derrubada das medidas provisórias, que estão alterando as regras de acesso ao salário desemprego e a benefícios como pensão por morte de cônjuge, e fazem parte do plano de ajuste fiscal da presidenta (El País, seção Brasil, 13/03/2015, grifos nossos).
\end{abstract}

Nesse exemplo, as nomeações contribuem para materialização de diferentes efeitos de sentido. É o que ocorre, por exemplo, na nomeação "Sindicatos e movimentos sociais", que figura no título da notícia e que, depois, no corpo desta, é retomada pela expressão "Confederações de trabalhadores, sem-teto e semterra". Essas duas expressões materializam o efeito de que há, por parte daqueles que historicamente apoiaram o PT e o governo Dilma, "cobranças" (vão cobrar) em relação às medidas provisórias do referido governo. Além disso, o enunciador materializado no excerto refere-se à ação dos "sindicatos e movimentos sociais" chamando-a de "manifestação", enquanto que, ao se referir à ação daqueles que pedem o impeachment, o termo usado é "ato". Essas duas formas distintas de nomear ações, em princípio, semelhantes mostra que há, para esse enunciador, uma diferença entre a "manifestação", termo historicamente vinculado às ações realizadas por grupos de esquerda, e o "ato", termo menos marcado ideologicamente, pois pode caracterizar qualquer ação, política ou não; o que cria, portanto, um efeito de neutralidade ${ }^{10}$. Vale salientar ainda que, enquanto os agentes que realizarão a manifestação são identificados duas vezes no texto (uma como "Sindicatos e movimentos sociais"; e outra como "Confederações de trabalhadores, sem-teto e

${ }^{10}$ É importante esclarecer que não defendemos a existência de uma suposta neutralidade vinculada ao termo "ato", pois defendemos que não existem palavras ou expressões neutras. Trata-se de um efeito de neutralidade, que surge pela seleção de um termo e não de outro. A esse respeito, remetemos o leitor aos textos de Conte (2003) e Francis (2003). Esses autores tratam do fenômeno da "rotulação anafórica" e mostram que a seleção de uma expressão referencial ou de um nome como rótulo de uma porção de texto depende de diferentes fatores textuais e/ou discursivos. 
Cadernos de ESTUDOS LINGUÍSTICOS (58.1) - jan./abr. 2016

sem-terra"), os que farão o "ato que pede o impeachment" não são nomeados, o que produz um efeito de generalização, ou seja, é como se, com exceção dos que farão parte da "manifestação" e que já foram devidamente identificados, todo o restante da população, ou boa parte desta, constituísse o grupo dos que pedem o impeachment. Em síntese, o principal efeito de sentido materializado nesse excerto é o de que mesmo os setores que apoiam o governo Dilma Rousseff e são contrários à sua saída, pois consideram o pedido de impeachment como "golpe", não estão totalmente satisfeitos com o atual governo.

Verificamos, assim, que, embora entre os manifestantes dos dois grupos haja uma regularidade discursiva acerca da insatisfação em relação ao governo Dilma, os objetivos de suas manifestações são antagônicos: "Impeachment Já" vs "Não vai ter Golpe", que podem ser traduzidos, ainda, como: "Fora Dilma" vs "Dilma Fica",o que indica uma polarização da sociedade. Essa polarização aponta para o que Maingueneau (2010) chama de dimensão enunciativopragmática da polêmica, pois, como mostramos nas análises das faixas presentes nas manifestações, há marcadores liguístico-enunciativos, que conferem certo "tom" de agressividade e/ou veemência àquilo que é encenado nas referidas manifestações (como é o caso da negação polêmica "Não vai ter golpe!”); mas há, também, um "dispositivo pragmático", que faz com que essas marcas linguísticoenunciativas adquiram sentido, pois, ainda segundo Maingueneau (2005, p. 191), a abordagem do registro polêmico "não pode limitar-se as marcas enunciativas", pois, além desses fatores, "o simples fato de sustentar uma polêmica pressupõe pragmaticamente que há uma crise na comunidade em questão, que os valores que a fundam estão ameaçados" (MAINGUENEAU, 2010, p. 192). No caso das manifestações anti-Dilma/PT/Lula e pró-Dilma/PT/Lula, o valor ameaçado é o da democracia, o qual, segundo Maingueneau (2005), passa a funcionar, no interior da polêmica, como uma norma geral, que impõe a ambos os lados da polêmica que eles devem polemizar. É justamente em torno das normas que regem essa suposta democracia que se estabelece a polarização. Tal polarização fica bem representada na imagem abaixo, em que os pró-governo aparecem à esquerda, de vermelho, e os anti-governo aparecem à direita, de verde e amarelo.

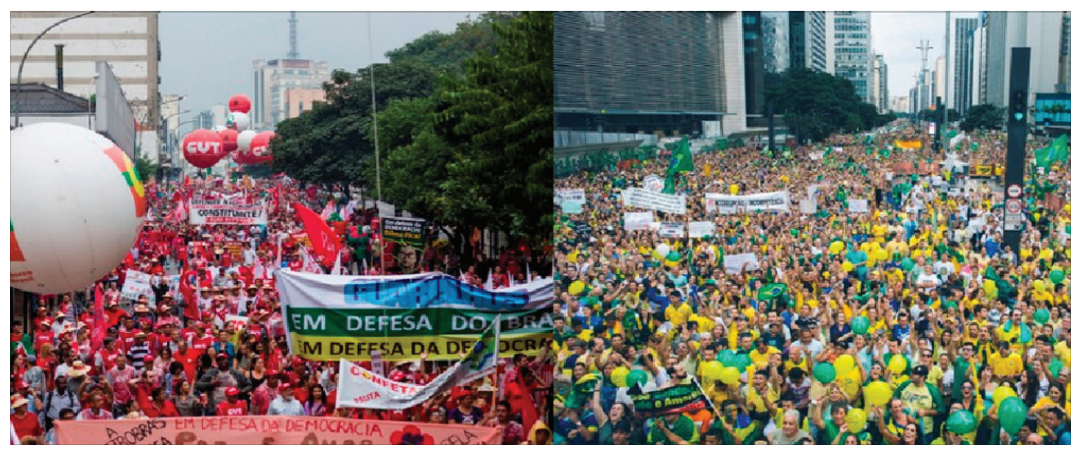

Figura 6: Montagem realizada pelo site http://brigadaspopulares.org.br/ de manifestações pró e contra o governo Dilma. 
Essa oposição se dá a partir dosefeitos de sentido atribuídos aos signos linguísticos e do efeito da memória discursiva sobre a atualidade do acontecimento. Memória essa que está relacionada ao posicionamento de cada grupo. Assim, quando os que defendem a saída de Dilma gritam "Impeachment Já", vestidos de verde e amarelo e levantando bandeiras do Brasil, eles retomam e reconfiguram a memória do Impeachment do ex-presidente do Brasil, Fernando Collor de Mello, em 1992. Esse foi o primeiro processo de impeachment de um presidente na América Latina, o qual foi desencadeado tanto por questões político-partidárias quanto por questões econômicas, essas últimas ligadas, principalmente,ao aumento da inflação e ao confisco das cadernetas de poupança. O impedimento de Collor foi uma decisão que marcou a política brasileira e, por isso, ao se retomar a memória do Impeachment de Collor para reforçar o pedido de saída de Dilma, atualiza-se um suposto efeito de justiça, pois se busca mostrar que, assim como no caso Collor de Mello, o impedimento de Dilma Rousseff é também uma atitude necessária para a preservação de um certo sentido de democracia.

Por outro lado, entre os defensores da permanência do governo Dilma, os quais substituem o termo impeachment pelo termo golpe, mediante justificativa de que não há nada provado contra a presidente, a tomada de posição pelo termo golpe no lugar do termo impeachment marca um posicionamento discursivo diferente do grupo anterior, indicando que este grupo está subjetivado em outro lugar e partilha de outro posicionamento discursivo. Ao optar pelo termo golpe, esse posicionamento, que chamamos aqui de pró-Dilma retoma uma memória discursiva acerca do início da Ditadura Militar ${ }^{11}$, também conhecido como Golpede 64, em que os militares retiraram do governo o presidente democraticamente eleito,João Goulart, e governaram o país entre os anos de 1964 a 1985, período caracterizado, na memória discursiva que circula na sociedade ${ }^{12}$, pela censura, supressão de direitos, perseguição política e repressão aos opositores do regime. Assim, ao associar o pedido de saída de Dilma a uma memória acerca do Golpe de 64, atribui-se a tal pedido um efeito de sentido segundo o qual há, por parte dos defensores desse "novo golpe", uma tentativa de ferir a democracia e a liberdade política do Brasil, desrespeitando, inclusive, o voto popular que elegeu a presidente Dilma Rousseff. Assim, verificamos que há, também, um deslizamento de sentido da palavra "democracia", pois, para os partidário do governo Dilma Rousseff, permitir o exercício da democracia é, justamente, não apoiar o suposto "golpe"; enquanto que, para os opositores do referido governo, o exercício da democracia consiste em viabilizar o impeachment de Dilma Rousseff, já que essa seria a "vontade do povo". Nesse caso, vemos o funcionamento do que Maingueneau (2010) chama de dimensão sociogenérica do polêmico. Trata-se, de

\footnotetext{
${ }^{11}$ Embora utilizemos a expressão "Ditadura Militar, é válido ressaltar que já há um movimento para substituição dessa nomenclatura. Defende-se hoje, entre muitos pesquisadores, a substituição dessa expressão por "Ditadura Civil-Militar", sob justificativa de que o regime vivido no Brasil nesse período foi resultado de um acordo de benefícios e apoios entre militares e setores empresariais civis.

${ }^{12}$ É preciso ressaltar que o discurso sobre a Ditadura, como todo discurso, é heterogêneo. Assim, embora circule, por um lado, efeitos de sentido negativos acerca desse período, por outro, também circula, entre uma parcela da sociedade, sentidos positivos, como a ideia de um período de prosperidade, havendo, inclusive, discursos que pedem o retorno dos militares ao poder.
} 
verificar "as práticas discursivas efetivas por meio das quais, em um lugar e em um momento dados, o polêmico se exerce" (MAINGUENEAU, 2010, p. 193). Diz respeito, portanto, a verificação do quadro institucional, do(s) gênero(s), do(s) suporte(s), dos lugares de difusão por meio dos quais o polêmico se inscreve. Ainda segundo Maingueneau, as polêmicas dos atuais debates políticos, materializadas e/ ou construídas por meios de comunicação de massa, como o rádio, a televisão e a internet, não duram muito tempo. Por isso, há a necessidade de certa dramatização, que prende a atenção do espectador sobre a polêmica, já que não há uma forte vinculação ideológica e/ou institucional. Assim, no caso da oposição entre golpe e impeachment, mesmo que haja uma memória acerca do início da ditadura militar de 1964, e também do impeachmentde Fernando Collor de Mello, tais memórias só funcionam se "ativadas" por um conjunto de indícios (linguísticos, enunciativos, imagéticos etc.) que circulam na mídia (televisão, jornais escritos, blogs, redes sociais, etc.) e que conferem a essas memórias um caráter de atualidade, de acontecimento. É o que ocorre no caso das fotografias das manifestações, "capturadas" pelas lentes dos fotógrafos e divulgadas por meio de montagens, como foi o caso da figura 6 , em que a montagem elaborada pelo site já indica a existência de uma polêmica, que se marca, principalmente, pela oposição entre as cores (vermelho vs verde e amarelo). Nesse caso, vemos que o polêmico "se inscreve em uma temporalidade específica, constitui um acontecimento enunciativo que adquire sentido em relação a outros da mesma série" (MAINGUENEAU, 2010, p. 193).

A polarização social ${ }^{13}$, marcada na figura 6,parece ter se acentuado ainda mais após a condução coercitiva do ex-presidente Lula para depor, na $24^{\mathrm{a}}$ fase da OperaçãoLava Jato ${ }^{14}$, na manhã do dia 4 de março de 2016. A forma de condução do ex-presidente Lula foi alvo de inúmeras manifestações (nas redes sociais, nas ruas de algumas cidades do país, etc.) favoráveis e contrárias à ação da Polícia Federal, ordenada pelo juiz Sérgio Moro. Tal ação intensificou a mobilização nas redes sociais, blogs e sites para a realização de mais uma manifestação contrária ao governo Dilma Rousseff, ao PT e à Lula, no dia 13 de março de 2016, e também a convocação de uma outra manifestação, na mesma data, contra o chamado "golpismo" 15 . Embora esse acirramento nas ruas ainda esteja por começar, já vemos a polêmica discursiva, gerada/mantida por esse novo acontecimento, materializando-se em diferentes veículos de mídia. Isso ocorre porque a "mediação midiática" não acontece de forma "isenta", tendo em vista que todo discurso, inclusive o midiático, fala a partir de um lugar.

\footnotetext{
${ }^{13}$ Aqui não podemos falar de uma polarização de "esquerda vs direita", pois há uma parcela da esquerda (representada por partidos como PSTU e PSOL) que não defende o governo da presidente Dilma Rousseff.

${ }^{14}$ A Operação Lava Java é uma investigação em andamento realizada pela polícia Federal e considerada por esta como a maior investigação de corrupção já realizada no Brasil. Tal operação teve início com a investigação de uma rede de doleiros que atuava em vários estados e, a partir das investigações, descobriu a existência de um grande esquema de corrupção na empresa estatal brasileira, Petrobrás, envolvendo políticos de diversos partidos e maiores empreitaras do país: Odebrecht e Andrade Gutierrez.

${ }^{15}$ Para evitar confronto em os manifestantes pró e contra o governo, em muitas cidades, como em São Paulo, o ato pró-governo foi adiado para o dia 18 de março de 2016; toda via, em algumas cidades, a manifestação foi mantida para o dia 13 de março.
} 


\section{A POLÊMICA EM DISCURSOS MIDIÁTICOS}

De acordo com Fonseca-Silva (2008, p. 1), “a mídia pode ser definida como um lugar de memória discursiva e como um lugar de fabricação espetacular e veiculação dos espetáculos políticos, entre outros". Dessa forma, segundo a referida autora, uma grande parcela das atividades políticas, hoje, realizam-se, em sua dimensão pública, instituída pelas redes midiáticas (seja na televisão, seja no rádio, seja na internet, sejam nas revistas de informação, dentre outras tantas, etc.). Uma explicação possível para tal fato está na afirmação de Guy Debord (1997), segundo a qual a política se desenrola sob o pano de fundo de sociedades espetacularizadas.

$\mathrm{Na}$ sociedade contemporânea, a mídia, ainda segundo Fonseca-Silva (2007, p. 25), funciona como um lugar de construção de memórias,como lugar de memória discursiva, e como lugar/espaço de interpretação, em queo"gesto de interpretação e, portanto, de construção/re-construção de memória discursiva, ocorre estabilização/desestabilização de sentido(s) e sedimentação de valores da sociedade na qual operam".

Com base nesses postulados, afirmamos que: i) a condução coercitiva do ex-presidente Lula foi um dos momementos mais espetaculares dos bastidores da política nos últimos meses, pois a maioria dos veículos de comunicação, de rádio, de televisão e da internet, dedicaram grande parte de sua programação do dia 4 de março e dos dias subsequentes para tratar desse acontecimento discursivo e de seus desdobramentos; e ii) cada veículo apresentou sua "visão" dos fatos, de acordo com o seu posicionamento discursivo, produzindo diferentes interpretações. Para confirmamos nossas hipóteses, analisamos, a partir dos títulos e leads de duas notícias,publicadas em dois diferentes veículos da mída impressa (as revistasonline "Veja", socialmente atribuída à direita, e "Carta Maior", que se autodeclara portal de esquerda brasileira e latino americana), a materialização de discursos acerca da condução coercitiva de Lula e também acerca do proferimento que o ex-presidente fez,logo após o depoimento do dia 4 de março. Vejamos, então, os dados:

\section{Operação contra Lula é desfecho de parceria Moro e impensa}

Do total de 44 ordens judiciais, 24 estão sendo realizado na capital, onde o ex-presidente foi levado em mandado de condução coercitiva

Figura 7: Revista Carta Maior, seção Política, 04/03/2016

\section{Ordem de captura contra Lula sacode o Brasil}

Lula é o primeiro alvo do golpe contra Dilma Rousseff. "Foi um gesto de prepotência do juiz Sérgio Moro", qualifica o ex-presidente

Figura 8: Revista Carta Maior, seção Política, 04/03/2016 


\section{Lula: 'Eu aprendi a andar de cabeça erguida'}

Garantindo que ira percorrer o país, o ex-presidente passou um recado aos que pretendem tirá-lo de cena: 'Eu não vou baixar a cabeça’

Figura 9: Revista Carta Maior, seção Política, 06/03/2016

Na figura 7, a nomeação da condução coercitiva de Lula como "Operação contra Lula", confere certa parcialidade à decisão do judiciário de realizar a condução de Lula, uma vezque pressupõe que tal ato foi articulado, deliberadamente, para prejudicar o ex-presidente. Essa forma de nomeação poderia ser substituída, por exemplo, pela expressão "Operação que investiga Lula", o que mudaria seu efeito de sentido. Assim, o primeiro enunciado aponta para uma objeção do enunciador Carta Maiorem relação ao ato de condução do presidente para depor. $\mathrm{Na}$ figura 8, além da repetição do termo "contra", o ato de mandado coercitivo é recategorizado como "ordem de captura"; além disso, no lead da reportagem, onde se apresentam as informações mais relevantes da notícia, tem-se a afirmação indireta de que o ato de condução de Lula foi parte de um "golpe" contra Dilma Rousseff, retomando o discurso dos manifestantes pró-governo Dilma,os quais defendem a existência de um golpe em curso contra o Governo Rousseff. Por fim, a figura 9 mostra o posicionamento do enunciador Carta Maior acerca do discurso que o ex-presidente Lula proferiu logo após o seu depoimento no dia 04 de março; os trechos selecionado para o título da notícia bem como para o lead apontam para uma avaliação positiva do enunciador em relação ao pronunciamento de Lula, pois a expressão "andar de cabeça erguida", relaciona-se como a memória do cidadão honesto, que nada teme.

Vejamos, agora, como essas notíciasforam apresentadas na/pela revista Veja:

\section{Lula vira alvo da Lava Jato, agora oficialmente}

Em sua $24^{a}$ fase, a operação faz busca no Instituto Lula, na casa do expresidente e o leva para depor

Figura 10: Revista Veja, seção Brasil, 04/03/2016

\section{Lula fez comício em vez de dar explicações}

Lula é conduzido coercitivamente a depor na Polícia Federal em São Paulo para esclarecer uma mínima parte de suas atribuições com a Justiça brasileira - mas já fez comício, em vez de dar explicações

Figura 11: Revista Veja, seção Brasil, 04/03/2016

\section{Lula ataca Moro e chama petista às ruas: 'A jararaca está viva'}

Ex-presidente culpou 'arrogância' do juiz federal pela operação desta sexta-feira, encerrou papel de vítima e provocou diversas vezes a força-tarefa da Lava Jato

Figura 12: Revista Veja, seção Brasil, 04/03/2016 
Na figura 10, por meio da expressão "agora oficialmente", o enunciador Vejamostra que Lula já era alvo da Operação Laja Jato, mesmo sem uma oficialização, ou seja, o enunciador mostra que havia um envolvimento de Lula com a referida operação, mesmo que tal relação não tivesse ainda sido oficializada (ou descoberta) pela justiça. No lead,verificamos uma tomada de posição em favor do mandado de condução coercitiva do ex-presidente Lula, pois a expressão "o leva para depor" suaviza, em certa medida, o efeito da "condução coercitivo", a qual, como o próprio nome indica, ocorre por meio de uma "coerção", ou seja, algo que é feito à força, obviamente, sem o consetimento daquele que está sendo "conduzido".Há, portanto, uma naturalização da forma como o ex-presidente Lula foi conduzido para depor. Além disso, como mostramos acima, tal coerção é apresentada como a simples oficialização de uma investigação que já existia. Na figura 11, o título indica uma tomada de posição contrária ao pronunicamento do ex-presidente Lula, ocorrido após seu depoimento em 4 de março. Nesse caso, a categorização dopronunciamento como sendo um "comicío", o que retoma uma memória sobre campanhas eleitorais, e o uso da expressão "em vez de", mostrando que o ex-presidente deveria ter feito algo (dado explicações), mas fez outra coisa (comício), indica que o ato do presidente frustou as expectativas do enunciador Veja, já que esse esperava por explicações, mas "ouviu" o que chamou de "comício", numa alusão ao fato de Lula ter, supostamente, utilizado a "condução coercitiva" como palanque para dar início a sua campanha eleitoral. No lead, essa oposição entre o que o enunciador Veja esperava e o que foi feito por Lula é ratificada pelo uso do operador argumentativo "mas", além disso a expressão referencial indefinada "uma mínima parte de suas atribulações com a justiça" produz o efeito de sentido de que há outras atribulações de Lula com a justiça, o que indica que o ex-presidente teria outras coisas para explicar à justiça, além daquelas apontadas na/pela Operação Lava Jato. Por fim, na manchete apresentada na imagem 12, o enunciador faz referência ao pronunciamento de Lula, no dia 4 de março, e diz que, no referido pronunciamento, "Lula ataca Moro". Além disso, no lead da notícia, o enunciador Veja afirma que "Lula encenou papel de vítima e provocou diversas vezes a força-tarefa da Lava Jato". Dessa forma, por meio de verbos como "atacar", "encenar" e "provocar", o enunciador Veja constrói uma imagem negativa do expresidente Lula. O verbo "atacar" indica um comportamento agressivo de Lula; o verbo "encenar" mostra certa artificialidade no comportamento do ex-presidente, e, por último, o verbo "provocar", em "provocou a força tarefa da Lava Jato" aponta para um desrespeito, por parte de Lula, com as autoridades que investigam o caso de corrupção na Petrobrás.

Em síntese, verificamos, nas duas revistas analisadas, a materialização de uma polêmica discursiva, pois cada uma delas "representa" posicionamentos antagônicos em relação ao funcinamento da democracia no Brasil e "mostram" como tal democracia foi exercida (ou foi negada) no caso do mandato de condução coercitivaemitido e executado pela justiça brasileira e que teve como alvo o expresidente Luiz Inácio Lula da Silva. Nesse caso, essa situação específica funciona como mais um indício de como a polêmica discursiva entre os "pró" e os "anti" Dilma/PT/Lula se posicionam no interior do espaço discursivo. 


\section{CONSIDERAÇÕES FINAIS}

Nas análises, verificamos que polêmica discursiva entre os manifestantes pró e anti Dilma/PT/Lula gira, principalmente, em torno da seguinte oposição discursiva: impeachmentvsgolpe. Esses dois termos retomam e reconfiguram duas memórias discursivas do campo político brasileiro: por um lado, o termo impeachmentretoma a memória do impedimento do ex-presidente Fernando Collor de Mello; por outro lado, o termo golpe retoma a memória da Ditadura Militar de 1964.

Contudo, para além dessa relação com a memória, a análise das imagens das manifestações e dos excertos de reportagens, bem como das manchetes e leads, permite-nos fazer algumas considerações acerca da dimensão semântica da polêmica que se estabelece entre os posicionamentos pró e anti Dilma/PT/Lula. De acordo com Maingueneau (2010), a dimensão semântica, dentre as três dimensões que ele aponta, é a menos evidente, pois "exige que se entre na construção da identidade semântica dos discursos engajados na polêmica, ligando a interação polêmica ao funcidonamento do campo discursivo do qual participam os posicionamentos em conflito" (MAINGUENEAU, 2010, p. 195). No caso da polêmica entre os contrários e os favoráveis ao governo Dilma Rousseff e também ao PT e ao ex-presidente Lula, é obvio que esta é uma polêmica que se dá no campo político-partidário. Mas, é preciso, no caso da dimensão semântica, ir mais adiante. Trata-se, ainda segundo Maingueneau, de verificar "se a relação com o adversário é um acidente exterior ou se ela é constitutiva da identidade do posicionamento". No caso da polêmica aqui analisada, defendemos que, como dito anteriormente, tal polêmica se estabelece, principalmente, devido à forma como os dois posicinamentos tratam a questão da democracia. Para os partidários do governo Rousseff (e do PT e de Lula), a democracia consiste em fazer valer o direito de uma maioria que elegeu Dilma e, por isso, a destituição do governo Rousseff equivale a um "golpe político", que fere diretamente a democracia. Para os anti-governo, a democracia, que também corresponde ao direito de uma maioria, será exercida se houver o impeachment, já que esse é o desejo dos brasileiros que foram às manifestações amplamente divulgadas na/pela mídia. Se partirmos da lógica bakhtiniana de que a relação com o outro é constitutiva, podemos supor, como o faz Maingueneau, que as modalidades do polêmico "variam em função do posicionamento concernido" (MAINGUENEAU, 2010, p. 196). Nesse caso, alguns posicionamentos, devido a sua forma de constituição, são, naturalmente, mais polêmicos que outros. Assim, a política-partidária, por exemplo, se constitui basicamente por polêmicas, pois defender um partido é, necessariamente, se opor a um outro. Contudo, ainda em relação ao funcionamento dessa polêmica, verificamos que ela, ao contrário, por exemplo, da polêmica no campo religioso - como no caso da polêmica entre jansenistas e humanistas devotos (MAINGUENEAU, 2005), ou da polêmica entre Teologia da Libertação e Renovação Carismática Católica (SILVA, 2006) - não se constitui por um retorno aos princípios do próprio campo, já que o campo político é constitutivamente movediço, mas de um retorno às verdades de campos vinculados a discursos fundadores, como é caso do campo religioso e do campo filosófico. Em relação a esse último, verificamos que a polêmica entre os anti e os pró Dilma/PT/Lula se fundamenta exatamente na forma como o campo político partidário se apropria de conceitos do campo filosófico, como o de bom senso, o de honestidade, e o de justiça. 


\section{REFERÊNCIAS}

BARBOSA, L. C. Mídia e discursividade: Dilma, Lula, radicais do PT e corrupção. Vitória da Conquista: UESB, 2014. Dissertação (mestrado), Universidade Estadual do Sudoeste da Bahia, Programa de Pós-Graduação em Linguística, Vitória da Conquista, 2014.

DEBORD, G. A sociedade do espetáculo. Trad. Estela dos Santos Abreu. Rio de Janeiro: Contraponto, 1997 [1967].

FONSECA-SILVA. M. da C. Mídia e lugares de memória discursiva. In: FONSECA-SILVA, M. da C. e POSSENTI, S. (Org.). Mídia e redes de memória. Vitória da Conquista: Edições UESB, 2007. p. 11-37.

FONSECA-SILVA, M. C. Entre o verbal e o não verbal: memória e encenação discursiva da corrupção em Veja. In: Anais do XXIII Encontro Nacional da ANPOLL, 2008. Goiânia. XXIII Encontro Nacional da ANPOLL - Grupo de trabalho em Análise do Discurso, 2008. p. 1-3.

HENRY, P. A ferramenta imperfeita: língua, sujeito e discurso. Trad. Maria Fausta P. de Castro. Campinas/SP: Editora da UNICAMP, 1992.

MAINGUENEAU, D. (1984). Gênese dos discursos. Trad. Sírio Possenti. Curitiba, Criar Edições, 2005.

MAINGUENEAU, D. As três facetas do polêmico. In: Doze conceitos em Análise do Discurso. POSSENTI, S. e SOUZA-E-SILVA, M. C. P. de (Orgs.). Trad. Adail Sobral [et. al.]. São Paulo: Parábola Editorial, 2010, p. 187- 198.

PÊCHEUX, M. O Discurso: Estrutura ou Acontecimento. Tradução: Eni P. Orlandi, 5a. ed. Campinas, SP: Pontes Editores, 2008 [1983b].

SILVA, E. G. Os (des)encontros da fé: análise interdiscursiva de dois movimentos da Igreja Católica. Campinas, SP: IEL/UNICAMP. Tese (doutorado), 2006. 